\title{
PANAMÁ, UN PAÍS ABIERTO EN CANAL
}

\section{PANAMÁ, THE COUNTRY AND THE CANAL}

\author{
AUTOR \\ Enrique Ríos Vicente \\ Universidad Complutense de Madrid y Presidente de la SEECI (España) \\ enrios@eucmax.eim.ucm.es
}

\section{RESUMEN}

Los Tratados Torrijos-Carter otorgan a Panamá los plenos derechos de administración del Canal y obligan a las fuerzas militares estadounidenses a abandonar progresivamente el país. Al tener un gran tránsito de naves interoceánicas, el canal precisa de una ampliación para satisfacer tan elevada demanda. Esta ampliación consta de varias fases: la primera es geográfica (Corte Gaillard) para cubrir la demanda de las compañías de transporte y la segunda es la construcción de un tercer módulo de esclusas, con el elevado gasto de agua dulce y económico que conlleva. Existe una división entre EEUU y Panamá para debatir los aspectos económicos y de seguridad del Canal.

\section{PALABRAS CLAVE}

Torrijos- Carter - Ampliación - Canal - EEUU 


\section{ABSTRACT}

Torrijos-Carter Treaties give the full rights of Panama Canal administration and force the U.S. military to leave the country gradually. Having a large inter-oceanic ships transit the channel requires an extension to meet such high demand. This extension consists of several phases: the first is geographical (Gaillard Cut) to meet the demands of carriers and the second is the construction of a third module locks, with high input of freshwater and cost involved. There is a split between the U.S. and Panama to discuss economic and security aspects of the Canal.

\section{KEY WORDS}

Torrijos-Carter - Extension - Channel - USA

\section{ÍNDICE}

1. Realidad y perspectivas del canal interoceánica

2. Bibliografía

El 31 de Diciembre de 1999, de conformidad con los Tratados Torrijos-Carter, Panamá deberá entrar en posesión plena de la administración del Canal Interoceánico y las fuerzas militares estadounidenses en territorio panameño, desde el siglo XIX, deberán abandonar el país. No hay ninguna razón válida en el Derecho Internacional para que no se cumpla con la transferencia canalera, a pesar que, con motivo de la Invasión estadounidense de 1989, el Ejército panameño quedó disuelto, 
constitucionalmente se convino en 1994 que Panamá no tendría efectivos militares: ¿cuál será entonces el núcleo militar encargado de la custodia del Canal en los próximos años?; ¿qué uso tendrán las áreas militares utilizadas por el Comando Sur?; ¿cuáles son las alternativas de los panameños para el Canal?; ¿cómo se garantizará el régimen de neutralidad en Panamá?

Estas son algunas de las tantas interrogantes que el cumplimiento del pacto canalero plantea y que serán objeto de debate entre académicos españoles, mexicanos y panameños en un momento crucial e histórico para el comercio internacionales y el proyecto latinoamericano de integración regional. Los aportes de las ciencias sociales españolas, mexicanas y panameñas pueden convertirse, en éste momento, en un significativo espacio para el debate de temas como la democracia, los derechos humanos, el desarrollo económico, el derecho internacional, entre otros.

\section{Realidad y perspectivas del canal interoceánico}

El Canal de Panamá como vía interoceánica de 80 kilómetros, construida con la participación de 75 mil hombres y mujeres, es la obra de ingeniería más relevante del siglo XX. Durante décadas, el Canal y las áreas adyacentes al mismo, fueron aprovechadas por los Estados Unidos en beneficio de sus intereses económicos y políticos. Pero luego de un sin número de luchas el pueblo panameño condicionó la negociación de un pacto canalero con Estados Unidos, para redefinir la situación semicolonial que regía en el istmo desde principios del siglo XX. En 1977 se materializó la firma de los Tratados del Canal. Los Tratados Torrijos-Carter, firmados por Omar Torrijos H. y Jimmy Carter entraron en vigencia el 1 de octubre de 1979 y finalizarán el 31 de diciembre de 1999, cuando Panamá recupere su soberanía sobre esa franja de su territorio y alcance la administración plena del Canal. Se trata, por 
tanto, de dos procesos complementarios, reversión de tierras adyacentes al Canal y transferencia de la Administración en el Canal.

El Tratado Torrijos-Carter establece en su orden la transferencia de la Administración del Canal; la reversión de las áreas adyacentes al Canal; y el cierre de las bases militares. El 31 de diciembre de 1999 representa entonces, una fecha histórica que cancela en lo formal la Agenda nacional y militar. Al mismo tiempo, supone la renovación del proyecto de unidad estratégica para enfrentar el nuevo escenario una vez se registre, en la práctica. el perfeccionamiento del Estado y el país en su conjunto avance hacia otra modalidad capitalista de desarrollo. Porque el calendario de reversión de bienes pactado en los acuerdos canaleros significa, también, el tránsito desde una relación unas veces colonial y otras veces semicolonial hacia una situación neocolonial plena. Al mismo tiempo, el 31 de diciembre de 1999 representa la cancelación de la agenda militar en tanto se relata del Istmo el último soldado estadounidense; por lo que el escenario emergente plantea diversos debates, entre ellos la seguridad del espacio adyacente al Canal de Panamá, el uso de ese espacios y las estrategias para la circulación rápida de naves por la vía interoceánica.

A través de los acuerdos Canaleros se establece una reversión gradual al Estado Panameño de 89,182 hectáreas (tierras y aguas) de las cuales 72.122 forman parte de la cuenca del Canal. 11,800 son tierras rurales para reservas y parques y 5,260 están destinadas al desarrollo urbano de las provincias de Panamá y Colón. Los bienes incluyen 34,123 hectáreas, con 4,800 edificios, 3,690 unidades de viviendas y otras facilidades urbanísticas.

Para el año 1996, Estados Unidos había transferido a Panamá 1.294 edificios y 11.250 hectáreas de propiedades militares, incluidas las bases de Fuerte Amador, Fuerte Gulick, Fuerte Davis. el complejo escolar Margarita y la escuela Cristóbal. Antes del 31 de diciembre de 1999, Estados Unidos debe transferir a Panamá otros 
REVISTA DE LA SEECI.

Ríos Vicente, Enrique (2000): Panamá, un país abierto en canal. № 6. Noviembre

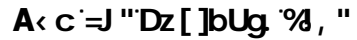

,661 血

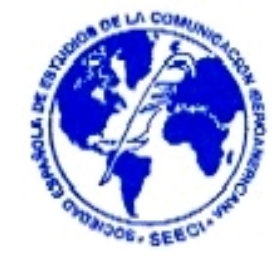

3.596 edificios y 26.000 hectáreas de uso militar. Esto representó, en su momento, una reducción gradual de las tropas estadounidenses de 10,400 en 1994 a 6,800 en 1996 y 4,410 en 1997. En 1999, última fase del cumplimiento de los tratados Torrijos-Carter, revertirán 22 instalaciones, la última de ellas, el 22 de diciembre, ubicada en el número 1501 entre Balboa Industrial y Corozal Oeste.

Sin embargo, asociada a la reversión se encuentra la utilidad del Canal. El incremento del tránsito de Naves y el avance del comercio marítimo mundial demanda la ampliación de la vía Interoceánica. La utilidad del Canal depende entonces de dos estrategias dependientes y complementarlas: la primera, el ensanchamiento del Corle Gaillard; y, la segunda, la decisión de la administración panameña entre la construcción de un tercer juego de esclusas y la construcción de un Canal a nivel. En el primer caso. existe la necesidad de ampliar el Corte Galllard de 12,6 kilómetros de largo y 152 metros de ancho, con los que cuenta actualmente, a 192 metros de ancho en las rectas y 222 metros en las curvas. El costo del ensanche asciende a unos 200 millones de dólares, pero con esa ampliación se facilitaría el tránsito de naves y la capacidad del Canal para enfrentar de la demanda de las compañías de transporte y carga Internacional en el siglo XXI.

La segunda estrategia, la construcción de un tercer juego de esclusas o la planificación de un del Canal a nivel, por tanto sin esclusas, se encuentra todavía en debate. La opción que cuenta con mayores simpatías es el tercer juego de esclusas, que servirá para ampliar el tránsito y permitiría la circulación rápida de los buques Panamá, con mangas de 30,5 metros, tamaño máximo de las embarcaciones que pueden transitar por las actuales las esclusas del Canal: el transito de buques Panamax por el Canal aumentara proporcionalmente del 27\%, unas 3.600 naves, en 1995, al 33\%, para el año 2010.

Pero, si se construye un tercer juego de esclusas se presenta otro problema, la 


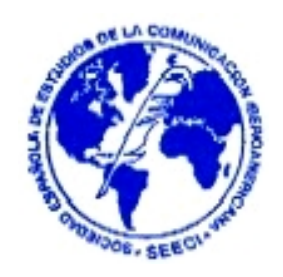

operación del Canal requiere el uso de 7,2 mil millones de litros de agua dulce cada día para llenar las esclusas; esta cantidad de agua. que se almacena por precipitación pluvial, en el interior de la Cuenca del Canal, con una extensión de 325 mil hectáreas, se encuentra afectada por los cambios climatológicos como el efecto invernadero, el fenómeno del niño y modificaciones urbanas como la estrategia de desarrollo económico para dicha zona geográfica. Las estrategias de desarrollo para la región interoceánica, hasta ahora planteadas. Incluyen, entre otros, centros turísticos, zonas procesadoras para la para exportación, ciudad del saber, centros para carga y descarga de contenedores. Ninguna de las alternativas contempla el desarrollo sostenible de la cuenca del Canal.

En las estrategias de desarrollo el problema ambiental aparece en un segundo plano. Tampoco se mencionan entre las estrategias la seguridad de Canal, que puede encontrar una solución con la contracción de una empresa privada de seguridad, para vigilar las 160 hectáreas del complejo Canalero.

Sin embargo, el 7 de Septiembre de 1977 Panamá y Estados Unidos de América firman dos convenios internacionales, el «Tratado Torrijos-Carter», concerniente a la transferencia del Canal y el «Tratado Concerniente a la Neutralidad y el Funcionamiento del Canal». El Tratado Torrijos-Carter cierra el proceso de descolonización y la etapa del capitalismo iniciada en la década del 30. La situación neocolonial queda ahora regida por el Tratado Concerniente a la Neutralidad y el Funcionamiento del Canal de Panamá que establece los fundamentos del régimen de neutralidad del país y el mecanismo de seguridad del área adyacente al Canal.

Ese régimen de neutralidad, desconocido por la población panameña, es el eje de los actos de agresión realizados, en la década del ochenta, por Estados Unidos en contra de Panamá, en tanto el proceso de neutralización del Istmo limita y descalifica todas y cada una de las acciones unilaterales de las administraciones estadounidenses. 


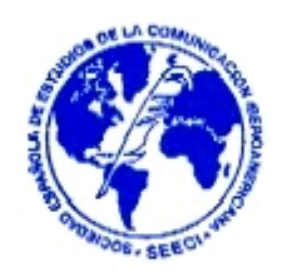

Esas agresiones tienen diversos sentidos y perspectivas y se desarrollan desde el ámbito de las relaciones diplomáticas mediante la Reserva Nunn y la Enmienda Deconccini e incluyen actos directos de intervención militar como los registrados e! 20 de diciembre de 1989 y el 5 de diciembre de 1990.

Sin embargo, las relaciones entre Panamá y los EE. UU., por intereses diversos plantea dos escenarios, por un lado la descontaminación de las bases militares y los polígonos de tiro; por el otro, las negociaciones para la presencia militar estadounidense en et Istmo después del año 2000. Esta división permite presiones por parte de Estados Unidos y planteamientos contrapuesto por parte del Estado y los gobiernos panameños: el problema del Canal se desdobla ahora en lo económico y (a seguridad militar. Lo político como estrategia para la planificación del uso de los recursos derivados del Canal y la neutralidad como mecanismo de seguridad son ahora hechos ajenos al debate de fondo, según los planteamientos de los especialistas en Derecho internacional afines a las posiciones expuestas desde 1978 por el Senado estadounidense.

La separación entre lo político y lo económico permite reorganizar la visión del interés nacional, pero margina el debate público sobre las alternativas del principal recurso del Istmo: si antes lo económico pasaba por ampliar el consenso político entre las clases sociales, hoy, la estabilidad de lo económico tiene relación directa con las actividades de las clases sociales al margen del consenso político. Esta transición desde el consenso político hacia el consenso legal fue posible mediante un complejo proceso donde el dólar se queda, la administración del Canal se transfiere a Panamá, las áreas revertidas son vendidas al capital transnacional y las bases militares se negocian por etapas. Ese cuadrilátero configura, sin embargo, el espacio de desarrollo del capitalismo panameño en el siglo XXI.

Sin duda alguna, la Administración panameña del Canal, enfréntala diversos retos, 
REVISTA DE LA SEECI.

Ríos Vicente, Enrique (2000): Panamá, un país abierto en canal. No 6. Noviembre Año IV. Páginas: 1-8.

ISSN: 1576-3420 DOI: http://dx.doi.org/10.15198/seeci.2000.6.1-8

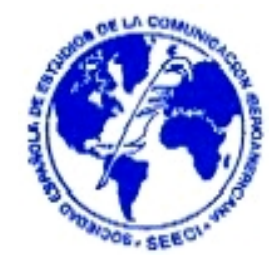

que deben solucionarse con algo más que creatividad. Por tal motivo, el Congreso Panamá, un país abierto en Canal, quiere convertirse en un foro para el debate y la discusión de propuestas para el Canal del siglo XXI. 